\title{
Formation of Carbon Aerogels From Glucose and as Adsorbents for Removal of Methylene Blue
}

\author{
Tongyan Ren ${ }^{1}$, Yuanyuan $\mathrm{Han}^{2}$, Mengmeng Zhang ${ }^{2}$, Bianli Zhang ${ }^{2} \&$ Xinglong Gou ${ }^{2}$ \\ ${ }^{1}$ Department of chemistry, North Sichuan Medical College, Nanchong, China \\ ${ }^{2}$ College of Chemistry and Chemical Engineering, Chemical Synthesis and Pollution Control Key Laboratory of \\ Sichuan Province, China West Normal University, Nanchong, China \\ Correspondence: Xinglong Gou, College of Chemistry and Chemical Engineering, Chemical Synthesis and \\ Pollution Control Key Laboratory of Sichuan Province, China West Normal University, Nanchong, China. Tel: \\ 189-9072-7960. E-mail: rtyhp223@163.com
}

Received: February 8, 2014 Accepted: March 10, 2014 Online Published: March 26, 2014

doi:10.5539/jmsr.v3n2p74 URL: http://dx.doi.org/10.5539/jmsr.v3n2p74

\begin{abstract}
In this communication, Carbon aerogels were prepared by hydrothermal process using glucose as raw material and the structure and morphology were characterized by XRD, SEM, and IR. Methylene blue was removed by employing the as-prepared nano materials as adsorbent. The maximum adsorption capacity determined from the Langmuir adsorption isotherm was $819.67 \mathrm{mg} \cdot \mathrm{g}^{-1}$ and adsorption kinetics and adsorption isotherms were also studied.
\end{abstract}

Keywords: dyes, carbon aerogels, adsorption, methylene blue

\section{Introduction}

Dyes, which make the world colorful and charming, are widely used in the field of leather industry, printing industry, textiles industry, plastics, cosmetic industries and so on. However, dyes also have been bringing about a lot of environmental pollutions (Bhatnagar \& Jain, 2005). Moreover, a large amount of dyes and pigments are toxic naturally and may cause serious diseases such as skin and eye irritation, allergic dermatitis, skin cancer as well as aberration (Eren \& Afsin, 2009). Therefore, during the past decades, intensive attention has been paid to the removal of dyes. Chemical, physical and biological methods, which mainly including advanced oxidation, ozonation decomposition, adsorption, coagulation, flocculation, ultrafiltration, and extraction, biosorption were the most popular technologies have been developed nowadays (Ghaedi, Hassanzadeh, \& NasiriKokhdan, 2011; Yao, Wang, \& Qi, 2009; Abd EI-Latif, Ibrahim, \& EI-Kady, 2010; Vimonses, Lei, Jin, Chow, \& Saint, 2009). However, none of the above-mentioned methods were succeed in completely removing the dyes from wastewater because most of the methods often suffer from one or more boundedness. Interestingly, adsorption method is regarded as the most promising methods for removal of dyes and treatment of wastewater (Ai, Zhang, $\&$ Chen, 2011).

Carbon aerogel a novel form of cellular carbonaceous adsorbent, has been developed and has excellent adsorption properties recently. Basically, carbon aerogel, which has well-defined porous structure, high specific surface areas, is a representative cellular carbonaceous material (Moreno-Castilla \& Maldonado-Hódar, 2005; Long et al., 2009). So far, there were a large number of reports on the adsorption of organic dyes (X. B. Wu, D. C. Wu, Fu, \& Zeng, 2012) and inorganic (especially metal ions) based on carbon aerogel (Al-Anber \& Matouq, 2008; Meena, Mishra, Rai, Rajagopal, \& Nagar, 2005). Therefore, for the further application of carbon aerogel, it was meaningful to explore the adsorption properties of carbon aerogel so as to obtain adsorbent with faster adsorption rate and higher adsorption capacity.

\section{Materials and Method}

\subsection{Synthesis of Carbon Aerogels}

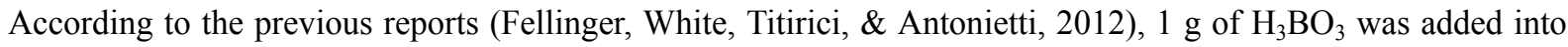
$15 \mathrm{ml}$ deionized water and slightly heated to dissolve, then sodium hydroxide was added in portion to tune the $\mathrm{pH}$ at 9-10, after that $5.4 \mathrm{~g}$ of glucose was added to $12 \mathrm{ml}$ of the as-prepared solution. After stirred violently for $0.5 \mathrm{~h}$, the mixture was then shifted to a $25 \mathrm{~mL}$ autoclave, sealed and heated at $180{ }^{\circ} \mathrm{C}$ for $8 \mathrm{~h}$. After cooled to 
ambient conditions, the mixture was washed and dried to yield the target products. The carbon aerogels were characterized before their application.

\subsection{Characterization of the Carbon Aerogels}

Characterization of the crystal structure and morphologies of Carbon aerogels were performed by using X-ray diffraction (XRD, $\mathrm{Cu} \mathrm{K \alpha}$, radiation Rigaku Ultima IV), Scanning Electron Microscope (SEM, JEOL JSM-6510LV) and Infrared Spectroscopy (IR, Thermo Scientific Nicolet 6700).

\subsection{Batch Adsorption Experiments}

In a thermostatic oscillator, the experiments were performed by placing an appreciate amount of carbon aerogels adsorbent in a certain volume of solution at different concentrations of methylene blue. About $4 \mathrm{~mL}$ of the suspension was extracted in a certain interval, and was separated by centrifugation. A UV-Vis Spectrometer was adopted to analyze the obtained supernatant in order to confirm the concentration of methylene blue. The adsorption capacity $(q)$ of the adsorbent can be calculated by Equation (1)

$$
q=\frac{\left(c_{0}-c_{e}\right) V}{m}
$$

In the equation, $c_{0}$ and $c_{e}$ are the original and the equilibrium concentration of methylene blue $\left(\mathrm{mg} \cdot \mathrm{L}^{-1}\right)$, respectively, and $m$ is the mass ( $\mathrm{g}$ ) of the Carbon aerogels, and $V$ is the total volume (L) of methylene blue solution.

\section{Results and Discussions}

\subsection{Crystal Structure of Carbon Aerogels}

The carbon aerogels were characterized by XRD, IR, and SEM. The XRD pattern of the carbon aerogels was exhibited in Figure 1a), as can be seen clearly that only in the vicinity of $24^{\circ}$ has a wide peak, which is due to the reaction of carbon through an amorphous carbon, and the crystallinity is low, the peak bit wider. Figure 1b) demonstrates the infrared spectrum, the peak at $3400 \mathrm{~cm}^{-1}$ corresponds to the absorption of $-\mathrm{OH}$, and the peak at $1030 \mathrm{~cm}^{-1}$ corresponds to the absorption of $\mathrm{C}-\mathrm{OH}$, the two peaks clearly indicate that a large amount of carbon-OH exist in the spherical surface. The peak at $1620 \mathrm{~cm}^{-1}$ can be ascribed to the conjugated olefin skeleton caused by vibration, while the peak at $1700 \mathrm{~cm}^{-1}$ are induced by the $\mathrm{C}=\mathrm{O}$ stretching vibration. A great number of hydrophilic functional groups $-\mathrm{OH}$ and $\mathrm{C}=\mathrm{O}$ exist in the carbon surface of the ball, which obviously improve its dispersibility in aqueous solution. The SEM image of the dispersive nanosphere was shown in Figure 2, and the average diameter is approximately $200-300 \mathrm{~nm}$.
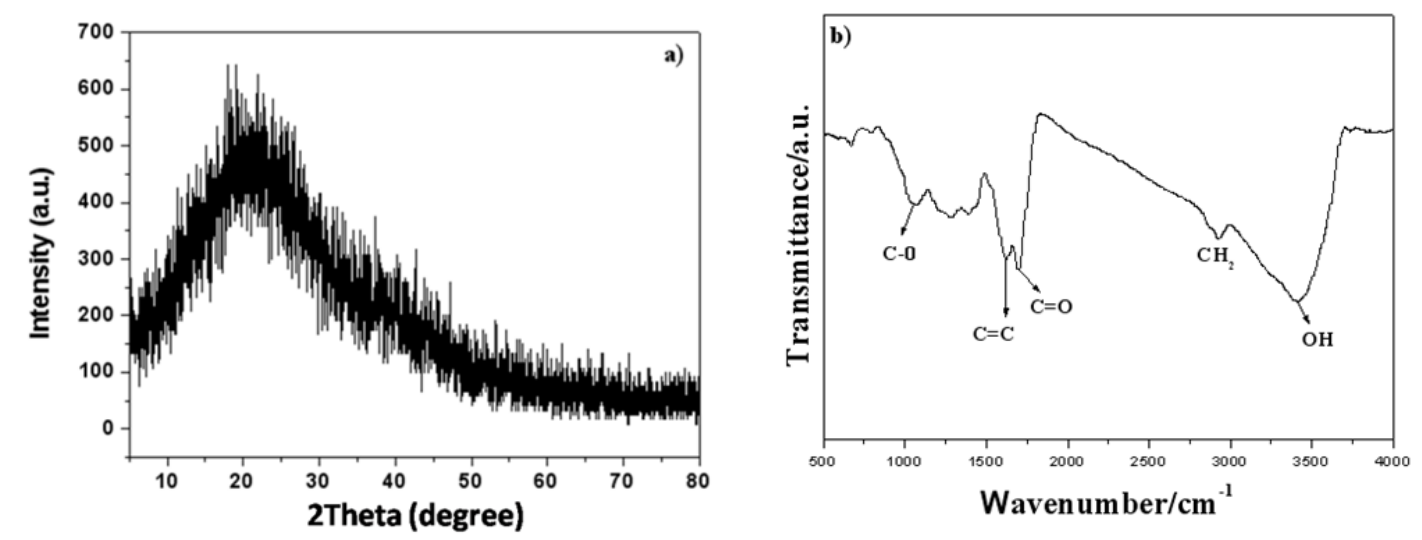

Figure 1. XRD pattern (a) and IR spectrogram (b) of Carbon aerogels 


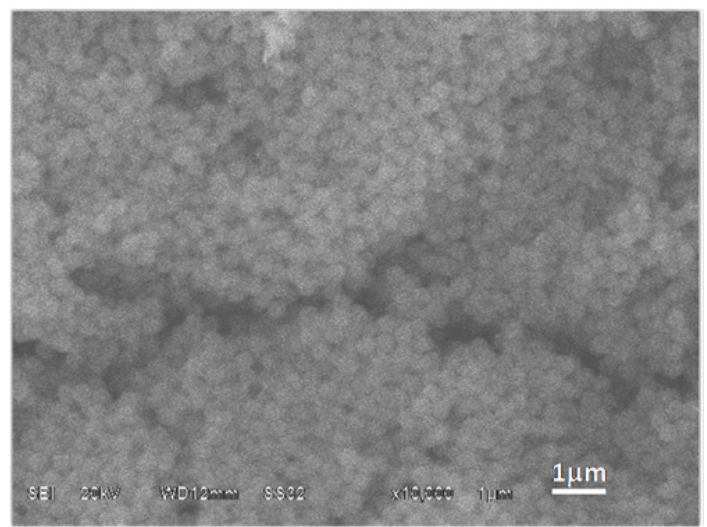

Figure 2. SEM of Carbon aerogels

\subsection{Effect of Contact Time}

In each batch experiment, $50 \mathrm{~mL}$ of initial $\mathrm{MB}$ aqueous solution with the concentration of $100 \mathrm{mg} \cdot \mathrm{L}^{-1}$ and $15 \mathrm{mg}$ carbon aerogels were put in a beaker flask. The mixture solution was agitated in a thermostatic oscillator under ambient conditions. The samples were extracted at certain intervals and centrifuged. UV-Vis Spectrometer was adopted to determine the concentration of MB left in the supernatant solution at $664 \mathrm{~nm}$. Figure 3 demonstrates that adsorption capacity of MB was affected markedly by contact time by using the carbon aerogels as adsorbent. It was obvious that the adsorption capacities increase rapidly in the first $10 \mathrm{~min}$ and then slow increase and reach equilibrium after $30 \mathrm{~min}$.

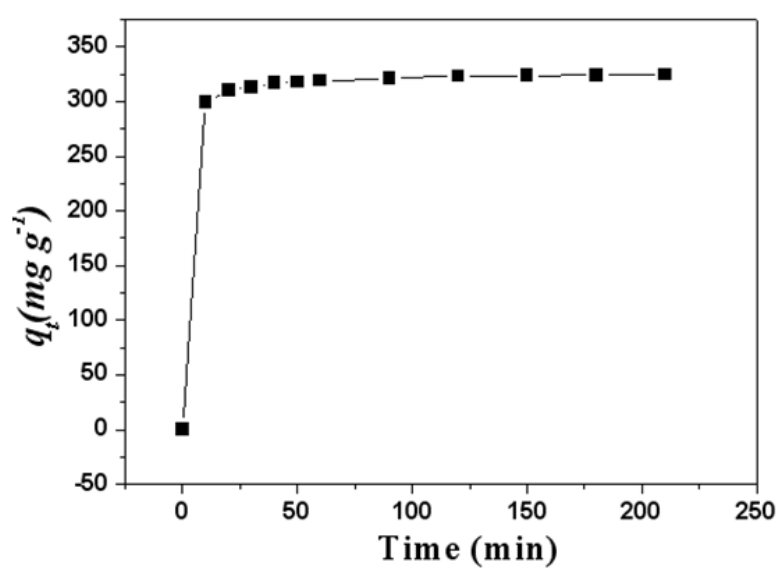

Figure 3. Effect of the contact time on adsorption

\subsection{Adsorption Kinetics}

To explore the intrinsic mechanism of the adsorption process, experimental data are analyzed by employing the pseudo-first-order and pseudo-second-order (Figure 4).

The pseudo-first-order equation can be given by (Khataee, Vafaei, \& Jannatkhah, 2013)

$$
\log \left(q_{e}-q_{t}\right)=\log q_{e}-\frac{k_{1} t}{2.303}
$$

In the equation, $q_{\mathrm{e}}$ and $q_{t}$ stand for the amounts of $\mathrm{MB}$ adsorbed $\left(\mathrm{mg} \cdot \mathrm{g}^{-1}\right)$ at equilibrium and time $t$ (min), respectively, $k_{l}$ stands for the rate constant of pseudo-first-order $\left(\mathrm{min}^{-1}\right)$. Values of $k_{l}$ can be calculated from the plots of $\log \left(q_{e}-q_{t}\right)$ versus $t$ for Equation (2).

The pseudo-second-order equation can be given by Equation (3) (Cherifi, Bentahar, \& Salah, 2013).

$$
\frac{t}{q_{t}}=\frac{1}{k_{2} q_{e}^{2}}+\frac{t}{q_{e}}
$$



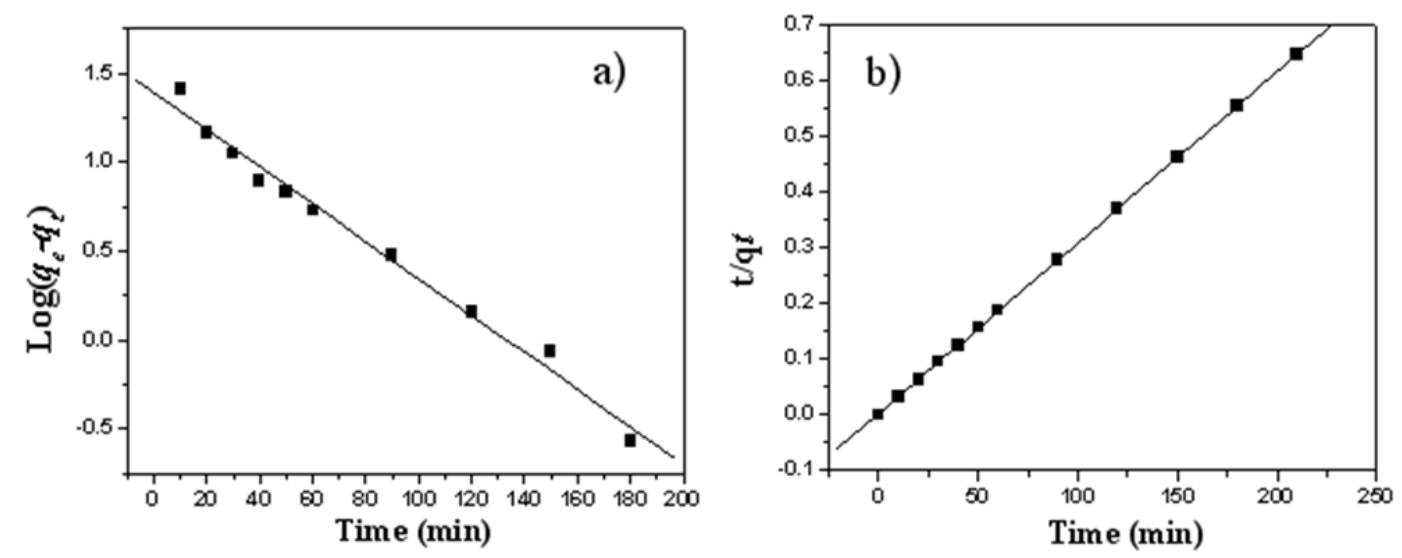

Figure 4. Adsorption kinetics: a) pseudo-first-order plot; b) pseudo-second-order plot

In the Equation (3), $k_{2}$ stands for the pseudo-second-order rate constant $\left(\mathrm{mg} \cdot \mathrm{g}^{-1} \cdot \mathrm{min}\right)$. The values of $1 / q_{e}$ and $1 / k_{2} q_{e}^{2}$ are yielded by the slope and intercept of the linear plots of $t / q_{t}$ against $t$ for Equation (3).

By linear regression for the two models, the kinetic constants were obtained, which are summarized in Table 1. Obviously, with regard to the pseudo-first-order model, the correlation coefficients $\left(\mathrm{R}^{2}\right)$ are relatively low, and the calculated $q_{e}$ values $\left(q_{e, c a l}\right)$ does not accord with the experimental data $\left(q_{e, e x p}\right)$, indicating that the MB adsorption on the Carbon aerogels does not fit to the pseudo-first-order model. Usually, this model does not fit well to the whole range of contact time in many cases. The pseudo-first-order equation is applicable only to the initial stage of the adsorption processes. In contrast, as far as the pseudo-second-order model is concerned, the $q_{e, c a l}$ values conform very well to the experimental results, indicating there are a good linear relation with $\mathrm{R}^{2}$ above 0.999. Therefore, the conclusion can be drawn that the adsorption process follows the pseudo-second-order model.

Table 1. Kinetic parameters for adsorption of MB onto the Carbon aerogel

\begin{tabular}{lll}
\hline & Kinetic parameters & MB \\
\hline & $q_{\mathrm{e}, \mathrm{exp}}\left(\mathrm{mg} \cdot \mathrm{g}^{-1}\right)$ & 324.56 \\
& $q_{\mathrm{e}, \mathrm{cal}}\left(\mathrm{mg} \cdot \mathrm{g}^{-1}\right)$ & 24.59 \\
Pseudo-first-order & $k_{1}$ & 0.024 \\
& $\mathrm{R}_{1}{ }^{2}$ & 0.98718 \\
\hline \multirow{3}{*}{ Pseudo-second-order } & $q_{\mathrm{e}, \mathrm{cal}}\left(\mathrm{mg} \cdot \mathrm{g}^{-1}\right)$ & 325.73 \\
& $k_{2}$ & 0.00327 \\
& $\mathrm{R}_{2}{ }^{2}$ & 0.99998 \\
\hline
\end{tabular}




\subsection{Effect of Temperature and Adsorption Isotherms}

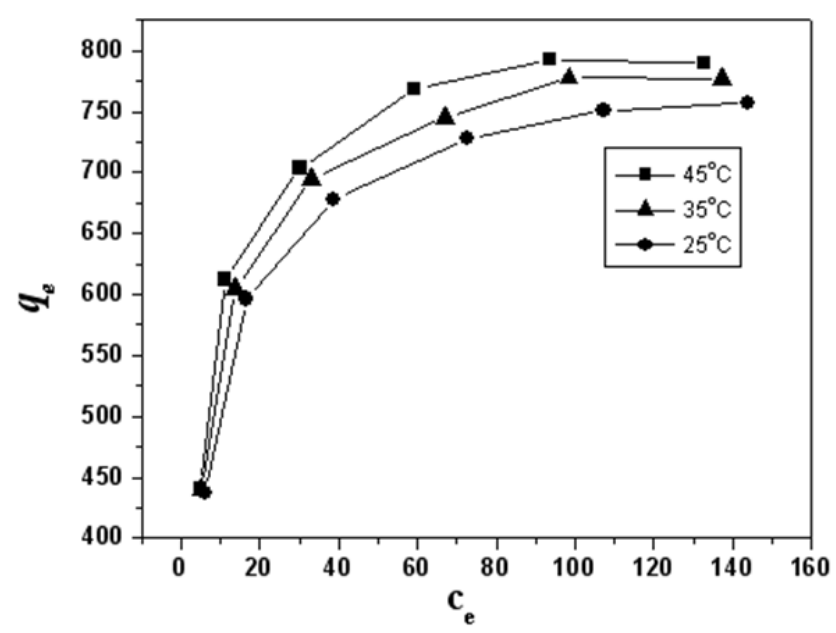

Figure 5. Effect of temperature on the adsorption of MB

To investigate the temperature effect on the adsorption, adsorption experiments were carried out at three different temperatures $\left(25,35\right.$, and $45{ }^{\circ} \mathrm{C}$ ) with distinct original concentrations (from 150 to $400 \mathrm{mg} \cdot \mathrm{L}^{-1}$ ). Figure 5 demonstrated the experimental results. From the results, we can see clearly that the MB adsorption capacities increase when the temperature increase, indicating that the adsorption process is endothermic naturally.

The specific relationship between the adsorption capacity of adsorbent and the concentration of adsorbate can be clearly described by adsorption isotherms. Therefore, it is crucial to design and determine an adsorption system. Usually, Langmuir and Freundlich isotherms equations are often applied to analyze the experimental results. Generally, the Langmuir isotherm is suitable to a process that adsorption surface is homogeneous and all the adsorption sites have equal adsorbate affinity.

The Langmuir isotherm equation can be exhibited by the following equation (Langmuir, 1918):

$$
\frac{c_{e}}{q_{e}}=\frac{1}{b q_{m}}+\frac{c_{e}}{q_{m}}
$$

In the equation, $q_{m}$ stands for the maximum capacity $\left(\mathrm{mg} \cdot \mathrm{g}^{-1}\right)$ and $b$ is a constant with respect to the energy of

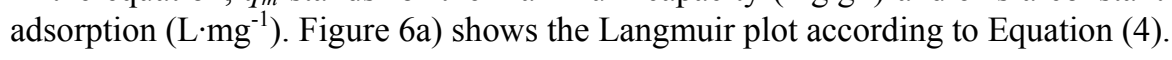

$\mathrm{R}_{\mathrm{L}}$, a dimensionless constant, can express the essential characteristics of the Langmuir isotherm and parameter is given by the following equation (Weber \& Chakravorti, 1974).

$$
\mathrm{R}_{\mathrm{L}}=1 /\left(1+\mathrm{b} c_{0}\right)
$$

In the equation, $c_{0}\left(\mathrm{mg} \cdot \mathrm{L}^{-1}\right)$ stands for the original $\mathrm{MB}$ concentration. The adsorption is favorable if the value of $\mathrm{R}_{\mathrm{L}}$ locates between 0 and 1 .

By comparison, the Freundlich isotherm model assumes heterogeneity of adsorption surfaces, and adsorption capacity is related to the equilibrium concentration of MB. The Freundlich isotherm equation is presented as follows (Freundlich, 1906).

$$
\log q_{e}=\log K_{f}+\frac{1}{n} \log c_{e}
$$

where $K_{f}$ stands for indicator of the adsorption capacity and $1 / n$ is the adsorption intensity.

For comparison, the Freundlich plot is also presented in Figure 6b) according to Equation (6). 

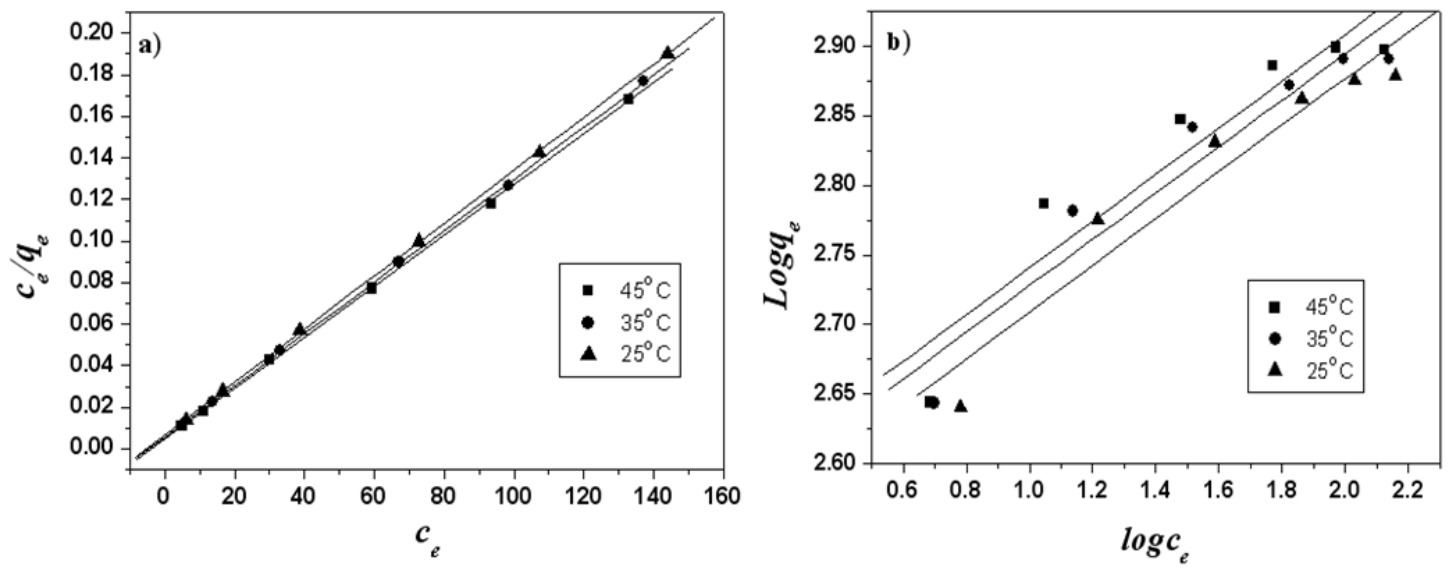

Figure 6. Langmuir (a) and (b) Freundlich isotherm plots at different temperatures

As are demonstrate in Table 2, the Langmuir model shows the high regression correlation coefficient, which indicates that the Langmuir model is more suitable than Freundlich model for depicting the adsorption equilibrium of MB by the Carbon aerogels. The maximum adsorption amount is $819.67 \mathrm{mg} \cdot \mathrm{g}^{-1}$ determined from the Langmuir isotherm.

Table 2. Adsorption isotherms constants for the adsorption of MB on Carbon aerogel

\begin{tabular}{|c|c|c|c|c|c|c|c|c|}
\hline & \multirow[b]{2}{*}{ Temp. } & \multicolumn{4}{|c|}{ Langmuir } & \multicolumn{3}{|c|}{ Freundlich } \\
\hline & & $q_{m}$ & $b$ & $\mathrm{R}_{1}^{2}$ & $\mathrm{R}_{\mathrm{L}}$ & $\overline{k_{F}}$ & $\mathrm{n}$ & $\overline{\mathrm{R}_{2}{ }^{2}}$ \\
\hline \multirow{3}{*}{ MB } & 298 & 787.40 & 0.1865 & 0.9951 & 0.0133 & 347.31 & 5.949 & 0.9242 \\
\hline & 308 & 806.45 & 0.2160 & 0.9998 & 0.0115 & 363.89 & 5.990 & 0.9213 \\
\hline & 318 & 819.67 & 0.2455 & 0.9999 & 0.0102 & 374.30 & 5.964 & 0.8919 \\
\hline
\end{tabular}

The thermodynamic parameters including the standard free energy $\left(\Delta \mathrm{G}^{\mathrm{o}}, \mathrm{kJ} \cdot \mathrm{mol}^{-1}\right)$, enthalpy $\left(\Delta \mathrm{H}^{\mathrm{o}}, \mathrm{kJ} \cdot \mathrm{mol}^{-1}\right)$ and entropy $\left(\Delta \mathrm{S}^{\mathrm{o}}, \mathrm{J}^{\mathrm{mol}}{ }^{-1} \cdot \mathrm{K}^{-1}\right)$ for the process of $\mathrm{MB}$ adsorption on the Carbon aerogels were calculated using the equations as follows (Gupta, Ali, \& Saini, 2007).

$$
\begin{gathered}
\Delta G^{\circ}=-R T \ln (b) \\
\Delta H^{\circ}=R \frac{T_{2} T_{1}}{\left(T_{2}-T_{1}\right)} \ln \left(\frac{b_{2}}{b_{1}}\right) \\
\Delta S^{\circ}=\frac{\Delta H^{\circ}-\Delta G^{\circ}}{T}
\end{gathered}
$$

In the equations, $T$ stands for absolute temperature (K), $R$ stands for the gas constant $\left(8.314 \mathrm{~J} \cdot \mathrm{mol}^{-1} \cdot \mathrm{K}^{-1}\right)$, and $b$ stands for Langmuir constant at a specific temperature studied here. Table 3 exhibited the results calculated by the above equations. From the results, a conclusion can be drawn that the MB adsorption on the Carbon aerogels is endothermic and entropy production, which indicates that the adsorption process is a spontaneous process and can occur at any given temperature.

Table 3. Thermodynamic parameters at different temperatures

\begin{tabular}{llll}
\hline \multicolumn{4}{l}{ Thermodynamic parameters } \\
Temp.(K) & $\Delta G^{\mathrm{o}}\left(\mathrm{kJ} \cdot \mathrm{mol}^{-1}\right)$ & $\Delta H^{\mathrm{o}}\left(\mathrm{kJ} \cdot \mathrm{mol}^{-1}\right)$ & $\Delta S^{\mathrm{o}}\left(\mathrm{J} \cdot \mathrm{mol}^{-1} \cdot \mathrm{K}^{-1}\right)$ \\
\hline 298 & -30.08 & 10.82 & 137.21 \\
308 & -31.47 & & 137.30 \\
318 & -32.85 & & 137.33 \\
\hline
\end{tabular}


In conclusion, Carbon aerogels were prepared by hydrothermal process using glucose as raw material and the structure and morphology were characterized by XRD, SEM, and IR. Methylene blue was removed by employing the as-prepared nanomaterials as adsorbent. The maximum adsorption property is $819.67 \mathrm{mg} \cdot \mathrm{g}^{-1}$ determined from the Langmuir isotherm and the adsorption kinetics and adsorption isotherms were also studied. The excellent adsorption property indicates the huge potential application of the Carbon aerogels for removal of dyes from wastewater.

\section{Acknowledgements}

The authors acknowledge financial support from Foundation (CBY13-A-QN32).

\section{References}

Abd EI-Latif, M. M., Ibrahim, A. M., \& EI-Kady, M. F. (2010). Adsorption equilibrium, kinetics and thermodynamics of methylene blue from aqueous solutions using biopolymer oak sawdust composite. Journal of American Science, 6, 267-283.

Ai, L., Zhang, C., \& Chen, Z. (2011). Removal of methylene blue from aqueous solution by a solvothermal-snthesized grapheme/magnetite composite. Journal of Hazardous Materials, 192, 1515-1524. http://dx.doi.org/10.1016/j.jhazmat.2011.06.068

Al-Anber, Z. A., \& Matouq, M. A. D. (2008). Batch adsorption of cadmium ions from aqueous solution by means of olive cake. Journal of Hazardous Materials, 151, 194-201. http://dx.doi.org/10.1016/j.jhazmat.2007.05.069

Bhatnagar, A., \& Jain, A. K. (2005). A comparative adsorption study with different industrial wastes as adsorbents for removal of cationic dyes from water. Journal of Colloid and Interface Science, 281, 49-55. http://dx.doi.org/ 10.1016/j.jcis.2004.08.076

Cherifi, H., Bentaha, R. F., \& Salah, H. (2013). Kinetic studies on the adsorption of methylene blue onto vegetal

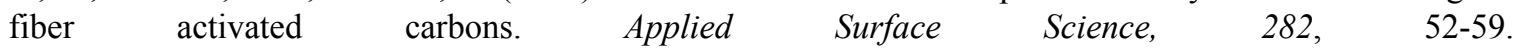
http://dx.doi.org/10.1016/j.apsusc.2013.05.031

Eren, E., \& Afsin, B. (2009). Removal of basic dye using raw and acid activated bentonite samples. Journal of Hazardous Materials, 166, 830-835. http://dx.doi.org/10.1016/j.jhazmat.2008.11.132

Fellinger, T. P., White, R. J., Titirici, M. -M., \& Antonietti, M. (2012). Borax-Mediated Formation of Carbon Aerogels from Glucose. Advanced Functional Materrials, 22, 3254-3260. http://dx.doi.org/10.1002/adfm.201102920

Freundlich, H. M. F. (1906). Über die adsorption in löungen (Adsorption in solution), Z. Physical Chemistry, 57, 384-470.

Ghaedi, M., Hassanzadeh, A., \& NasiriKokhdan, S. (2011). Multiwalled carbon nanotubes as adsorbents for the kinetic and equilibrium study of the removal of alizarin red S and morin. Journal of Chemical \& Engineering Data, 56, 2511-2520. http://dx.doi.org/10.1021/je2000414

Gupta, V. K., Ali, I., \& Saini, V. K. (2007). Adsorption studies on the removal of Vertigo Blue 49 and Orange DNA 13 from aqueous solutions using carbon slurry developed from a waste material. Journal of Colloid Interface Science, 315, 87-93. http://dx.doi.org/10.1016/j.jcis.2007.06.063

Khataee, A. R., Vafaei, F., \& Jannatkhah, M. (2013). Biosorption of three textile dyes from contaminated water by filamentous green algal Spirogyra sp: Kinetic, isotherm and thermodynamic studies. International Biodeterioration \& Biodegradation, 83, 33-40. http://dx.doi.org/10.1016/j.ibiod.2013.04.004

Langmuir, I. (1918). The adsorption of gases on plane surface of glass, mica and platinum. Journal of the Americal Chemical Society, 40, 1361-1368. http://dx.doi.org/10.1021/ja02242a004

Long, D., Chen, Q., Qiao, W., Zhan, L., Liang, X., \& Ling, L. (2009). Three-dimensional mesoporous carbon aerogels: Ideal catalyst supports for enhanced $\mathrm{H}_{2} \mathrm{~S}$ oxidation. Chemical Communication, 26, 3898-3900. http://dx.doi.org/10.1039/B900808J

Meena, A. K., Mishra, G. K., Rai, P. K., Rajagopal, C., \& Nagar, P. N. (2005). Removal of heavy metal ions from aqueous solutions using carbon aerogel as an adsorbent. Journal of Hazardous Materials, 122, 161-170. http://dx.doi.org/10.1016/j.jhazmat.2005.03.024

Moreno-Castilla, C., \& Maldonado-Hódar, F. J. (2005). Carbon aerogels for catalysis applications: An overvies. Carbon, 43, 455-465. http://dx.doi.org/10.1016/j.carbon.2004.10.022 
Vimonses, V., Lei, S., Jin, B., Chow, C. W. K., \& Saint, C. (2009). Kinetic study and equilibrium isotherm analysis of Congo red adsorption by clay materials. Chemical Engineering Journal, 148, $354-364$. http://dx.doi.org/10.1016/j.cej.2008.09.009

Weber, T. W., \& Chakravorti, R. K. (1974). Pore and solid diffusion models for fixed-bed adsorbers. AIChE Journal, 20, 228-238. http://dx.doi.org/10.1002/aic.690200204

Wu, X. B., Wu, D. C., Fu, R. W., \& Zeng, W. (2012). Preparation of carbon aerogels with different pore structures and their fixed bed adsorption properties for dye removal. Dyes and Pigments, 95, 689-694. http://dx.doi.org/10.1016/j.dyepig.2012.07.001

Yao, Z., Wang, L., \& Qi, J. (2009). Biosorption of methylene blue from aqueous solution using a bioenergy forest waste: Xanthoceras sorbifolia seed coat. CLEAN - Soil, Air, Water, 37, 642-648. http://dx.doi.org/10.1002/clen.200900093

\section{Copyrights}

Copyright for this article is retained by the author(s), with first publication rights granted to the journal.

This is an open-access article distributed under the terms and conditions of the Creative Commons Attribution license (http://creativecommons.org/licenses/by/3.0/). 